\title{
EDITORIAL
}

\section{The Case for Case Reports}

If you are reading a hard copy of this editorial, then you are holding in hand the first issue of the American Journal of Perinatology Reports, or AJP Reports as we like to refer to it. Welcome to AJP Reports and thank you for taking the time to peruse it. I hope you find many of the reports interesting and helpful. The editorial team and publisher are very pleased to be able to bring this journal to our readers. Judging by the journal title, the editorial team, and the layout you may have already guessed that this is a companion to the American Journal of Perinatology. We will continue to publish original articles and topical reviews in the American Journal of Perinatology, but all case reports or case series will be referred to AJP Reports.

Some may question the need for more case reports. Our decision to start AJP Reports obviously indicates that we think that case reports can be useful. I can refer to several diseases, treatment complications, and procedures that were first brought to the attention of healthcare providers through case reports. The best example of the usefulness of case reports is probably in infectious diseases. In the early phases of an emerging infectious disease, the case report or case series are usually the first clues of a problem. HIV was first brought to the attention of the medical community by case reports. ${ }^{1-3}$ In our own field, the first attempts at treatment of twin-to-twin transfusion syndrome (TTTS) using laser coagulation were reported in a case series. ${ }^{4}$ After additional reports about the use of laser in TTTS, a randomized trial was performed that cemented laser photocoagulation as a therapeutic modality for TTTS. ${ }^{5}$ While case reports or series are not considered the highest form of evidence, they are frequently the first form of evidence and the nudge that starts the cascade of investigation that ultimately leads to high-level evidence. Therefore, their impact on clinical practice may be easily overlooked as it is usually several years down the road from their first publication.

In order for case reports or case series to have an impact, it is critical that they move the field forward and/ or provide an educational component. For these reasons, the editors of AJP Reports will look for evidence of the following qualifications when evaluating case reports or case series:

1. The report describes a novel test or procedure, or novel application of an established test or procedure.

2. The case reports a rare condition or complication, and includes an imbedded lesson. The emphasis is on the latter. If it is a report of some condition that has not been adequately reported in pregnancy or in the neonate, but is otherwise well described in nonpregnant women or adults, then it is important that the report provides novel insight into how the condition in the context of pregnancy or immediate postnatal period differs from what has been reported in the general population. The mere fact that it has not been adequately reported in pregnancy or the neonate cannot be the sole reason for publication. Obviously this criterion may be relaxed if this is the first report ever of such a condition or complication.

3. The case reported may be used as a springboard for a review of the condition and its management. In that case, the emphasis is on the review, which has to be informative. The judgment here will be based mostly on the quality of the review and its impact on dissemination of knowledge.

I would like to close by asking for your support of this new journal. Our goal is to provide our readers with useful information. As with every new endeavor, I ask for your patience and comments as we make it better. Do not hesitate to contact me or Dr. Higgins with any questions or comments. In the meantime, keep the cases coming.

\section{George R. Saade, M.D. ${ }^{1}$ Editor in Chief}

\section{REFERENCES}

1. Masur H, Michelis MA, Greene JB, et al. An outbreak of community-acquired Pneumocystis carinii pneumonia: initial manifestation of cellular immune dysfunction. N Engl J Med 1981;305(24):1431-1438
${ }^{1}$ Division of Maternal-Fetal Medicine, The University of Texas Medical Branch, Galveston, Texas.

Am J Perinatol Rep 2011;1:1-2. Copyright (C) 2011 by Thieme Medical Publishers, Inc., 333 Seventh Avenue, New York, NY 10001,
USA. Tel: +1(212) 584-4662.

DOI: http://dx.doi.org/10.1055/s-0031-1286597.

ISSN 2157-6998. 
2. Gottlieb MS, Schroff R, Schanker HM, et al. Pneumocystis carinii pneumonia and mucosal candidiasis in previously healthy homosexual men: evidence of a new acquired cellular immunodeficiency. N Engl J Med 1981;305(24):1425-1431

3. Siegal FP, Lopez C, Hammer GS, et al. Severe acquired immunodeficiency in male homosexuals, manifested by chronic perianal ulcerative herpes simplex lesions. N Engl J Med 1981; 305(24):1439-1444
4. De Lia JE, Cruikshank DP, Keye WR Jr. Fetoscopic neodymium:YAG laser occlusion of placental vessels in severe twin-twin transfusion syndrome. Obstet Gynecol 1990;75(6): 1046-1053

5. Senat MV, Deprest J, Boulvain M, Paupe A, Winer N, Ville Y. Endoscopic laser surgery versus serial amnioreduction for severe twin-to-twin transfusion syndrome. N Engl J Med 2004;351(2):136-144 